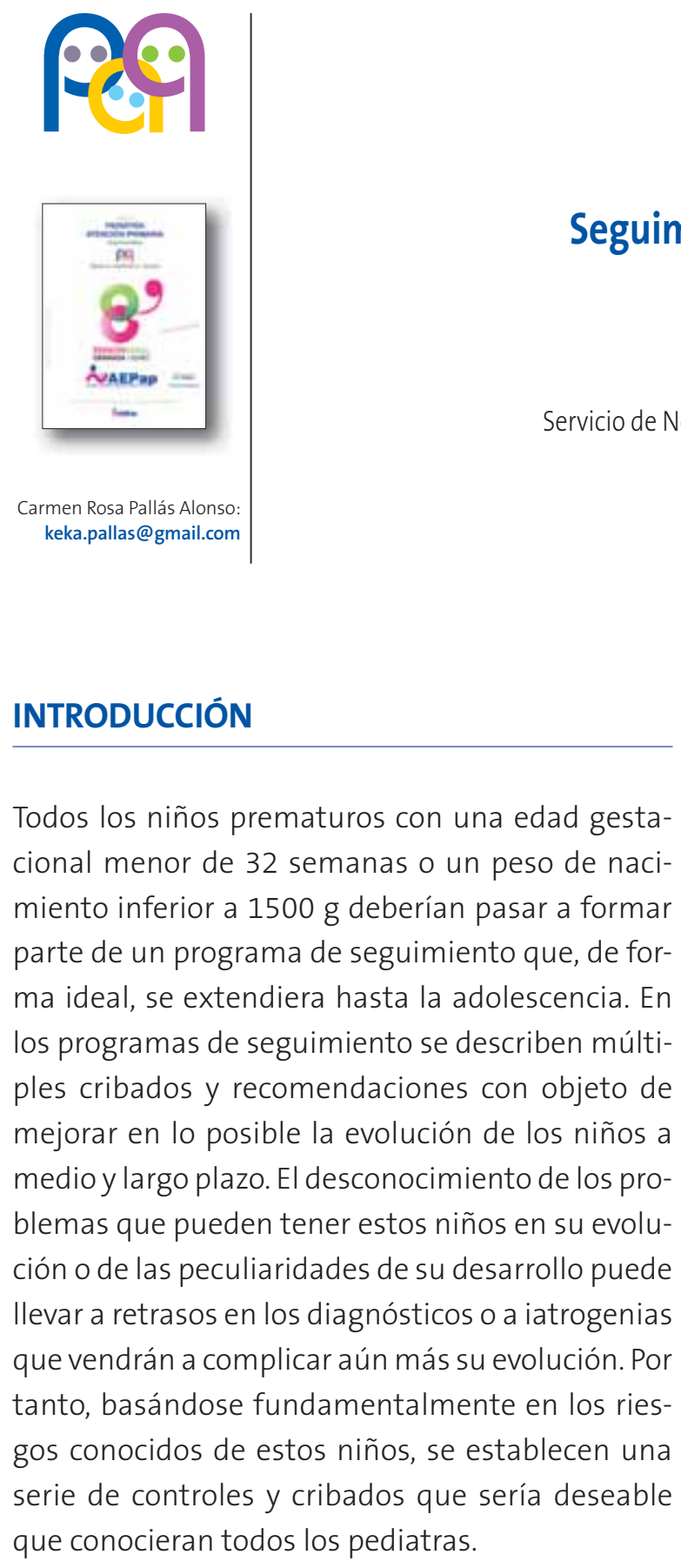

\section{PUNTOS CLAVE}

- El pediatra debe conocer el programa de seguimiento en el que está incluido el niño y confirmar que realmente acude a las revisiones y se realizan los controles rutinarios.

- El crecimiento insuficiente se asocia con problemas en el neurodesarrollo, la ganancia ex-

\section{Mesa redonda}

\author{
C. R. Pallás Alonso
}

cesiva se asocia a un riesgo mayor de presentar obesidad, enfermedad cardiovascular y diabetes.

- Se debe apoyar y promocionar la alimentación con leche materna tras el alta. Mejora el cociente de desarrollo y disminuye la tasa de reingreso.

- Los niños con riesgo de problemas motores se deben remitir a atención temprana así como todos aquellos en los que se detecte alguna alteración motora.

- Se confirmará que se ha realizado el cribado para la retinopatía de la prematuridad. Si no está hecho se debe remitir al niño sin demora a un oftalmólogo experto.

- Todos los recién nacidos con peso menor de 1500 g o una edad gestacional inferior a 32 semanas deben evaluarse en algún momento con potenciales evocados auditivos.

- Los niños de muy bajo peso presentan con mayor frecuencia que los niños a término alteraciones más complejas del comportamiento y psicopatología.

\section{CONFLICTO DE INTERESES}

Los autores declaran no presentar conflictos de intereses en relación con la preparación y publicación de este artículo. 


\section{LECTURA RECOMENDADAS}

- Pallás Alonso CR. Programa de Actividades Preventivas y de Promoción de la Salud para niños prematuros con una edad gestacional menor de 32 semanas o un peso inferior a 1500 gramos. Del alta hospitalaria a los 7 años. En: Recomendaciones Prevlnfad/ PAPPS [en línea] [actualizado en marzo de 2010] [consultado el 28/04/2011]. Disponible en www.aepap.org/previnfad/menor32-1500.htm.

Seguimiento del recién nacido menor de 1500 g más ampliado, con mayor información sobretodo en relación con aspectos motores, aportando escalas de valoración y algoritmos diagnósticos.
- Kangaroo mother care. Practical guide. World Health Organization, Department of Reproductive Health and Research [en línea]. Disponible en http://whqlibdoc.who.int/publications/2004/9243590359.pdf

Guía práctica sobre cómo realizar el método canguro. Instrucciones muy sencillas que se pueden dar a las madres de niños prematuros en general y sobre todo cuando está disminuyendo la cantidad de leche de madre.

- Wood E, Rosenbaum P. The gross motor function classification system for cerebral palsy: a study of reliability and stability over time. Dev Med Child Neurol. 2000;42:292-6.

Escala muy práctica y fácil de utilizar la valoración motora. 